\title{
Neurology and Therapy: Looking Back on 2018 and Forward to 2019
}

\author{
Marwan Sabbagh · Antonio Bertolotto
}

Received: January 9, 2019 / Published online: January 30, 2019

(C) The Author(s) 2019

Dear Readers,

We would like to first honour the promise we made at the end of 2018 , to offer fee waivers for publication in Neurology and Therapy of accepted manuscripts authored by each of our three most valued reviewers. We then take this opportunity to reflect on two articles published last year in Neurology and Therapy, which we feel are particularly impactful, and to speculate over the exciting opportunities which we hope will emerge throughout 2019 to advance knowledge on therapies for neurological indications.

Towards the end of 2018, in our end of year 'Acknowledgement to Authors, Referees, and Readers,' we highlighted our appreciation of the effort expended by all of our reviewers. In recognition of this, we are offering to each of the three most valued reviewers in 2018 a free publication for an accepted manuscript. Judging for this purpose was a more difficult task than we anticipated; our reviewers are dedicated and diligent, so we thank all of you once again. To meet our promise, however, we share (with their permission) the names of two of the reviewers, who we have chosen for this award.

M. Sabbagh $(\bowtie)$

Cleveland Clinic Lou Ruvo Center for Brain Health, Las Vegas, NV, USA

e-mail: Sabbagm@ccf.org

A. Bertolotto

University Hospital San Luigi Gonzaga, Turin, Italy
- Márcia Waddington Cruz, Federal University of Rio de Janeiro, Brazil.

- Lisa Walker, Ottawa Hospital Research Institute, Ontario, Canada.

Regarding articles we feel to be particularly impactful, we have each chosen one to which we would like to draw your attention, and the first of these is Dr Angelo Ghezzi's commentary on the 'European and American Guidelines for Multiple Sclerosis Treatment.' The commentary by Dr Ghezzi underscores the complexity and growth of multiple sclerosis (MS) treatments. With multiple bodies (ECTRIMS, EAN, and AAN) offering guidelines, there is a need to have perspectives on how the therapeutic field is evolving, what to anticipate, and how to apply knowledge in clinical practice. Dr Ghezzi's commentary informs the audience in such a manner.

A further article to which we have chosen to draw your attention is by Dr Yara Fragoso et al., 'Practical Evidence-Based Recommendations for Patients with Multiple Sclerosis Who Want to Have Children.' This review addresses an important topic, which affects the lives of many patients with MS. Knowledge in this field is advancing fast, and the review updates readers from the results of a meeting of Brazilian experts in March 2018. Further, although other recent reviews have also focused on pregnancy and MS, Dr Fragoso and her colleagues explore uncommon aspects such as symptomatic drugs often used for patients with MS, men with MS 
who want to have children, and assisted reproductive technology. In this review article, readers can find answers to questions which are extremely relevant to the everyday management of MS for patients who are planning to have children. The first author, Dr Fragoso, is an expert in pregnancy and MS and we are honoured that since publishing this review, she has kindly accepted our invitation to join the Editorial Board of Neurology and Therapy.

In addition to the articles mentioned above, we are also excited that last year's publications prompted feedback and discussion in the journal. Drs Brzezicki and Kobetić authored a letter on Dr Londos' article, 'Practical Treatment of Lewy Body Disease in the Clinic: Patient and Physician Perspectives,' which in turn prompted Editorial Board Member, Dr Müller, to author an Editorial around the same topic. Professor Giancarlo Comi et al. wrote a letter on Dr Annovazzi et al.'s article, 'A comprehensive review on Copemyl ${ }^{\circledR}$.' In both instances, the original authors responded to these letters, so thank you to all these authors for your careful contributions to scientific debate. We are delighted to see that the publications in $\mathrm{Neu}$ rology and Therapy are prompting this engagement, which can only help to advance knowledge for research and clinical practice.

Neurology has now for a generation been transforming from a diagnostically driven field to a therapeutically driven one and that trend will continue in 2019 . We will see advances in technology in ways that are exciting to behold and consider, including deep brain stimulation as a potential treatment for Alzheimer's disease (AD), MRI-guided focused ultrasound seeking new targets and new diseases to treat, with forays into Parkinson's disease and AD; and continued interest in transcranial magnetic stimulation and neurostimulation technologies.

2018 was an important year in the AD space. We had compelling but mixed results from trials investigating BACE inhibitors, RAGE inhibitors, plasma exchange, insulin/metabolic directed therapies, and monoclonal antibodies against amyloid and tau. Concomitantly, we saw major advances in biomarker development both in cerebral spinal fluid and in the periphery. 2019 will push forward with incremental progress but major readouts are projected in 2020 or 2021.

Further in 2019, we expect real-word data from new drugs for MS and for migraine, we will see new artificial intelligence applications in diagnosis, the results of new wearable devices to measure patients' performance in their everyday lives, and more patient-reported outcomes (PROs) in clinical trials.

We have discussed some of the topics above, on which we were honoured to publish last year, but there are exciting developments in therapies for many neurological indications expected this year, and we very much hope to publish research on these. Throughout 2019, therefore, we invite you, our readers, to consider submitting your work to Neurology and Therapy.

Happy New Year!

Marwan N. Sabbagh, Editor in Chief, USA.

Antonio Bertolotto, Editor in Chief, Europe.

\section{ACKNOWLEDGEMENTS}

Peer Review. Please note, contrary to the journal's standard single-blind peer review process, as an article written by the Editor-in-Chiefs of the journal this article was not peer reviewed.

Funding. No funding or sponsorship was received for this study or publication of this article.

Authorship. All named authors meet the International Committee of Medical Journal Editors (ICMJE) criteria for authorship for this article, take responsibility for the integrity of the work as a whole, and have given their approval for this version to be published.

Disclosures. Antonio Bertolotto received honoraria for serving on the scientific advisory boards of Biogen, Merck, Mylan, and Sanofi Genzyme, and received speaker honoraria from Biogen, Genzyme, Novartis, and TEVA; his institution has received grant support from Almirall, Bayer, Biogen, Genzyme, Merck, Novartis, TEVA, from the Italian Multiple 
Sclerosis Society, Fondazione Associazione Ricerca Biomedica ONLUS, and San Luigi ONLUS. Marwan Sabbagh-stock/ownership: uMethodHealth, Versanum, Brain Health Inc., NeuroTau. Advisory: Biogen, Lilly, VTV Therapeutics, Roche/Genetech, Allergan, Eisai, Grifols. CME: MedLearning Group, Miller Meded, Medscape, Rockpointe, Peerview Press.

Compliance with Ethics Guidelines. This article is based on previously conducted studies and does not contain any studies with human participants or animals performed by any of the authors.
Open Access. This article is distributed under the terms of the Creative Commons Attribution-NonCommercial 4.0 International License (http://creativecommons.org/licenses/ by-nc/4.0/), which permits any noncommercial use, distribution, and reproduction in any medium, provided you give appropriate credit to the original author(s) and the source, provide a link to the Creative Commons license, and indicate if changes were made. 